\title{
28 Research Square \\ Recurrent Colorectal Liver Metastasis Patients Would Benefit to Repeat Hepatic Resection
}

Wei Liu

Beijing Cancer Hospital

Jia-Ming Liu

Beijing Cancer Hospital

Kun Wang

Beijing Cancer Hospital

Hong-Wei Wang

Beijing Cancer Hospital

Bao-Cai Xing ( xingbaocai88@sina.com )

Peking University School of Oncology https://orcid.org/0000-0002-9854-2726

\section{Research article}

Keywords: CRLM, recurrence, repeat, resection, RFA

Posted Date: January 18th, 2021

DOI: https://doi.org/10.21203/rs.3.rs-146721/v1

License: (c) (i) This work is licensed under a Creative Commons Attribution 4.0 International License.

Read Full License

Version of Record: A version of this preprint was published at BMC Surgery on August 16th, 2021. See the published version at https://doi.org/10.1186/s12893-021-01323-y. 


\section{Abstract \\ Background}

Local treatment remains the best option for recurrent colorectal liver metastasis. The current study aims to investigate predictive factors of survival outcomes and select candidates of local treatment for CRLM at first recurrence.

\section{Methods}

Data were collected retrospectively on CRLM patients who underwent hepatic resection and developed first recurrence between 2000 and 2019 at our institution. A nomogram to predict overall survival was established based on a multivariable Cox model of clinicopathologic factors. The predictive accuracy and discriminative ability of the nomogram were determined by concordance index and calibration curve.

\section{Results}

Among 867 patients who underwent curative hepatic resection, 549 patients developed recurrence. Three hundred patients were evaluated to be resectable and liver-limited disease. Among of them, repeat liver resection and percutaneous radiofrequency ablation were performed in 88 and 85 patients, respectively. The other 127 patients only received systemic chemotherapy. Multivariable analysis identified nodepositive primary, tumor size $>3 \mathrm{~cm}$, early recurrence, RAS gene mutation and no local treatment were independent risk factors for survival outcome. Integrating these five variables, the nomogram showed good concordance statistics of 0.707 . Compared with patients who only received systemic chemotherapy, radical local treatment did not improve survival outcome significantly (median OS: 21 vs. 15 months, $p=$ 0.126) in high risk group (total score above 13).

\section{Conclusion}

Radical local treatment is crucial to prolong the survival of recurrent CRLM patients. The proposed model facilitates personalized assessment of prognosis for patients who developed first recurrence in liver.

\section{Key Summary}

More than half of CRLM patients developed recurrence after hepatic resection. The feasible and safety of repeat local treatment have been testified. The present study created a nomogram to select recurrent CRLM patient who would benefit from repeat local treatment. It helps to design a precision medicine schedule for recurrent CRLM.

\section{Background}


The liver is the most common site of colorectal cancer metastasis and approximately $50 \%$ of patients develop liver metastasis at some point during their disease course[1]. Hepatic resection is a potentially curative treatment for colorectal cancer liver metastasis (CRLM) patients, with 5-year survival rates of $30-50 \%[2]$. Unfortunately, more than half of patients recur after hepatic resection, and the majority of such recurrences occur within 2 years[3].

Recent advances in surgical approaches have dramatically changed the treatment strategy for patients with recurrent CRLM, which has allowed the description of risk factors for survival after second local treatment. Previous studies have provided evidence that repeat hepatic resection is feasible in selected patient with intrahepatic recurrences[4, 5]. However, who would maximum benefit from an aggressive treatment following first recurrence is not clear as there is paucity of data on the risk factors for survival on this patient population. There was no consensus introducing how to select candidates.

The present study aimed to investigate prognostic factors of survival and select candidates for local treatment of CRLM after first recurrence.

\section{Methods}

\section{Study Population}

From January 2000 to September 2019, a total of 1,027 patients underwent a curative hepatic resection for CRLM at the Hepatopancreatobiliary Surgery Department I of Peking University Cancer Hospital. The demographic and clinical data were retrospectively obtained from a prospectively collected patient database. Patients were enrolled study following criteria: 1 ) developed first recurrence after initial radical resection both of liver and primary tumor; 2) diagnosed to be resectable and liver-limited disease by multidisciplinary team (MDT); 3) no extrahepatic metastasis since the first hepatic resection; 4) no other simultaneous malignancies. The technical criteria of resectablitiy related to the liver remnant after resection: a) the anticipated ability to preserve two contiguous segments; $b$ ) the anticipated ability to preserve adequate vascular inflow, outflow and biliary drainage; $c$ ) the anticipated ability to preserve adequate future liver remnant volume (30\% in normal liver and $40 \%$ in pretreated liver with chemotherapy) [6]. The present study was approved by an Institutional Review Board.

\section{Preoperative Management for First Recurrence}

At the first recurrence, all patients underwent routine laboratory tests, including the measurement of the serum carcinoembryonic antigen (CEA) and carbohydrate antigen (CA)19-9 levels, and liver function tests. Routine imaging modalities, including enhanced computed tomography(CT) scan of abdominal, thoracic and pelvic region, and hepatic magnetic resonance imaging(MRI), were performed to determine the disease stage. Strict criteria were used to determine evidence of cancer recurrence (local or metastatic or second colorectal cancer). Recurrence was diagnosed by CT scans, MRI, PET-CT, or pathology proven recurrence (biopsy or specimen). All imaging reports that suggested recurrence were reviewed carefully and compared to baseline imaging reports to confirm that disease was not present at the time of liver 
resection. Preoperative chemotherapy was recommended to whom developed a heavy tumor disease burden (CRS>2) and/or recurred within a short period (disease free survival time less than 6 months) after first hepatic resection. The response to chemotherapy was evaluated by MRI, according to the Response Evaluation Criteria in Solid Tumors (RECIST 1.1)[7].

\section{Indications for Local Treatment}

The treatment strategy at first recurrence after hepatic resection was basically same with the first hepatic resection; that is, recurrent disease was treated locally only when the overall strategy was considered curative, all detectable lesions with a tumor-free margin. The resectablitiy was discussed and clinical treatment decision was made by MDT. Systemic chemotherapy was recommended if patient refused to second local treatment because of losing the faith of future. Resection of three or more segments was considered a major hepatic resection. Percutaneous radiofrequency ablation (RFA) was performed using the Celon system (Teltow, Germany) according to the manufacturer's instructions. The bipolar electrode needles were 16G, and guidance ultrasonography was performed using the Aloka a-10 (Tokyo, Japan) and GE Logiq E9 (Connecticut, USA) devices. In general, RFA was recommended in deeply situated tumors that would require extended resection of the normal parenchyma. RFA was contraindicated for: 1) the diameter of largest tumor size exceeding $3 \mathrm{~cm} ; 2$ ) tumor was adjacent to major bile ducts, larger blood vessels or colon/gallbladder were strictly restricted.

\section{Postoperative Work-Up}

After complete treatment, all patients underwent regular follow-up examinations with hepatic MRI and CT scan of abdominal/thoracic/pelvic region as well was the level of tumor marker were estimated every three months. Adjuvant chemotherapy was usually recommended[8].

\section{Statistical Analysis}

Continuous variables were summarized as means and categorical variables were summarized as frequency and percentage. The optimal cutoff points for the definition of early recurrence were determined using the minimum $p$ value approach that was calculated using the log-rank test for OS after first recurrence. Survival analyses were carried out using the Kaplan-Meier method and were compared using the log-rank test. OS was calculated from the date of local treatment or the date of systemic chemotherapy after first recurrence until death or last follow-up. It was always the primary endpoint for studies of repeat hepatic resection[3, 9]. Cut-off values for continuous variables were determined based on the C-statistic, with a Cox regression model for survival data including censored patients. The estimated cut-off values for each variable were: tumor number, 1-5; tumor size, 20-50mm; CEA level, 5 (higher limit of normal range), 10,20,50,100, 200ng/ml; CA19-9, 37 (higher limit of normal range), 50, 100units $/ \mathrm{ml}^{7}$. All statistical analyses were performed using SPSS 26.0 and R version 3.2.6 (http://www.rproject. org), and $p$ values $<0.05$ were considered statistically significant.

\section{Establishment of the nomogram}


Univariable and multivariable analyses of various clinicopathological factors by Cox's proportional hazard model were used to identify independent risk factors for OS in 300 patients. The results of the multivariable analysis developed an OS prediction nomogram with 1-,3-,5-year OS as the endpoints. The C-index was performed to assess the degree of discrimination, and calibration plots to visualize the agreement between the predicted and actual 1-, 3- and 5-year OS with bootstrapped samples. Using all categorical risk factors, we found the best separation in terms of survival by permutation and created two risk groups, a high-risk and a low-risk group.

\section{Results}

\section{Patient Characteristics}

There were 867 patients were eligible to be enrolled (Supplementary Figure 1). Recurrence was observed in $549(64.1 \%)$. Among of them, 523 patients (95.3\%) developed single site recurrence [liver ( $n=384)$, lung $(n=86)$, lymph node $(n=39)$, and other organ $(n=14)$ ], while 26 patients developed multiple organs recurrence. Among the patients with the single site of liver recurrence, 300 of them were defined to be technical resectablitiy by MDT. Repeat hepatic resection and percutaneous radiofrequency ablation were performed in 88 and 85 patients, respectively. There were 11 patients underwent R1 resection in repeat resection group. The other 127 patients refused to local treatment and only received systemic chemotherapy. In patients who had recurrence, the optimal cutoff point to define early recurrence was determined to be 6 months after hepatic resection, based on the results of the minimum $p$ value approach for survival after first recurrence $\left(p=7.57 \times 10^{-17}\right)$ (Supplementary Figure 2).

\section{Survival analysis}

The median followed up was 39 months since the first recurrence ( $95 \% \mathrm{Cl}$ : 35-43 months). The 1-, 3- and 5-year OS and DFS rates were $92.3 \%, 59.3 \%, 46.2 \%$, and $46.8 \%, 28.4 \%, 25.4 \%$ for 867 CRLM patients, respectively (Supplementary Figure 3). The 1-, 3- and 5-year OS for the local treatment group were $86.3 \%$, $54.1 \%$ and $38.9 \%$, respectively, and for the systemic chemotherapy group were $64.8 \%, 16.3 \%$ and $2.7 \%$, respectively. The difference was significant between two groups $(p<0.001)$ (Figure 1$)$. Of the 173 patients who underwent second local treatment, the 5 -year OS and DFS rate were $38.9 \%$ and $22.2 \%$, respectively (Supplementary Figure 4). Among of them, 97 patients (56.1\%) developed a second recurrence.

\section{Prognostic Factors for OS after First Recurrence}

In the univariable analysis, including primary $\mathrm{N}+$, tumor number $>1$, largest tumor size $>3 \mathrm{~cm}$, RAS mutation, early recurrence, bilateral distribution at first recurrence and no local treatment were related to a decreased OS $(p<0.05)$. Five independent prognostic factors for OS were identified in multivariable analysis: node-positive primary ( $\mathrm{HR}=1.857,95 \% \mathrm{Cl}: 1.227-2.809 ; \mathrm{p}=0.003)$, tumor size $>3 \mathrm{~cm}(\mathrm{HR}=1.707$, $95 \% \mathrm{Cl}: 1.037-2.810 ; p=0.036)$, early recurrence $(\mathrm{HR}=1.693,95 \% \mathrm{Cl}: 1.142-2.511 ; p=0.009)$, RAS mutation $(\mathrm{HR}=1.553,95 \% \mathrm{Cl}: 1.080-2.234 ; \mathrm{p}=0.017)$ and local treatment $(\mathrm{HR}=0.322,95 \% \mathrm{Cl}: 0.222-0.467 ; \mathrm{p}<0.001)$ (Table 2). 


\section{Prognostic Nomogram and Calibration for OS}

We developed a point based prognostic nomogram to predict OS at first recurrence based on the five independent prognostic factors (Figure 2). The sum of each score was presented in Supplementary Table 1. The $\mathrm{C}$-index of the prognostic nomogram was 0.707 for predicting $\mathrm{OS}$. The calibration plot suggested that the accuracy of predicted 1-,3-,5-year OS was excellent (Figure 3a,3b,3c).

\section{Performance of the Nomogram in Predicting OS}

In the development cohort, the AUCs of the nomogram score in predicting OS at 1, 3, and 5 years were higher than the Hof[10], Neal[11], and Serrano[12] recommended algorithm (Supplementary Figure 5 and Supplementary Table 2).

\section{Stratification by Nomogram and Indication for Repeat Local Treatment}

The survival curves stratified by quartiles of the nomogram predicted score are shown in Supplementary Figure 6. Compared with patients (total score above 13) who received systemic chemotherapy, radical local treatment did not improve survival outcome significantly before the decision was made (median OS: 21 vs. 15 months, $p=0.126$ ) (Supplementary Figure 7).

\section{Discussion}

Curative resection for CRLM is associated with long-term survival and cure opportunity; however, the majority of patients will develop recurrence[13]. It was well known that second hepatic resection is a safe and feasible procedure for patients with recurrent CRLM. Despite this, repeat hepatic resection may not be possible owing to anatomical or functional restraints $[9,10]$. RFA is a useful alternative in this situation. In several medical centers, surgeons selected patients for second hepatic resection according the same criteria as for the first initial resection. The disease characteristics, however, were not exactly identified between initial and recurrent time-point.

The indication and concerning prognostic factors of local treatment for first recurrence have not been well studied or defined. Previous analyses have been limited by small and single cohort of patients[4, 14]. In the present study, 173 patients who underwent local treatment at first recurrence for CRLM and the survival outcome were significantly better than whom only received systemic chemotherapy. The risk factors of tumor size $>3 \mathrm{~cm}$, node-positive primary, early recurrence, RAS mutation have been identified to be risk factors for survival outcome for first recurrent CRLM patients. Furthermore, in high-risk group (total score above 13), local treatment did not improve OS significantly (median OS: 21 vs. 15 months, $p=$ 0.126). The present model might facilitate to identify whom maximum benefit from repeat local treatment before the individualized treatment decision was made.

Recurrence occured in $60-84 \%$ of CRLM patients after first hepatic resection[15, 16]. The recent expansion of indications for surgery have led to an increase in the potentially resectable pool of patients, while they can also lead to an increased risk of early recurrence. Early recurrence has been reported to 
adversely influence survival after hepatic resection and therefore remains questionable for repeat hepatic resection because of their poorer prognosis[17, 18]. The present study investigated the optimal cutoff point of early recurrence was 6 months. Although it was still an independent prognostic risk factor, aggressive treatment should therefore be proactively considered even for cases of early recurrence.

The liver and lungs are the predominant sites of second recurrence, of which liver metastases are especially common $[3,19]$. Therefore, the present study only enrolled resectable patients with liver-limited disease at the first recurrence. Repeat hepatic resection for recurrence has been reported to be associated with an equivalent long-term outcome to first hepatic resection, with a similarly low surgical risk, and the 5-year OS rate ranged from 27 to 45\%[20-23]. RFA has emerged as an alternative radical treatment with less invasive and lower complication rate, which is effective for patients with comorbidities and recurrent liver disease[24, 25]. Previous studies of percutaneous RFA for recurrent CRLM are reasonable[26, 27]. It has suggested that tumor diameter and number are the most important factors that influence the effect[28, 29]. In our opinion, RFA was recommended in deeply situated tumors that would require extended resection of the normal parenchyma.

Given that the survival for patients who undergo liver resection for colorectal cancer metastases is long, surgeons and medical oncologists are now dealing with a "chronic disease" that should be treated differently depending on its presentation upon recurrence[30]. In the modern era, in addition to the current disease state of CRLM patients, recurrence should be concerned on when determining the treatment strategy. Preoperative chemotherapy might shrink and increase resectability. Especially, it also likely selected who would benefit from resection for recurrent patient. Therefore, it might be recommended for patients who developed early recurrence or heavy liver disease burden.

\section{Limitation}

The present study included its retrospective design and the gradual change in indications for resection and RFA over the study. First, although enrolled the patients were defined to be resectable, bias could still exist from patient selection in three groups. Second, it is possible that other unknown factors that will affect the accuracy of Nomogram model. At meanwhile, there was no cohort of external validation in the present study. Finally, all data were collected from a limited number of institutions.

\section{Conclusion}

Radical treatment remains the golden option for recurrent colorectal liver metastasis. The proposed model may help to predict the possibility of radical interventions $($ score $<13)$ and provide optimal individualized treatment.

\section{Abbreviations}


CRLM: colorectal liver metastases; RFA: radiofrequency ablation; OS: overall survival; DFS: disease free survival; MDT: multidisciplinary team; CEA: carcinoembryonic antigen; HR: hazard ratio; MRI: magnetic resonance imaging; CT: computed tomography;

\section{Declarations}

\section{Ethics approval and consent to participate}

The present study is a retrospective study and all subjects have given their written informed consent. The investigation project has been examined and certified by Ethics Committee of Beijing Cancer Hospital. The study was performed in accordance with the Declaration of Helsinki.

\section{Consent for publication}

The manuscript does not contain any individual person's data.

\section{Availability of data and materials}

The datasets generated and/or analyzed during the current study are not publicly available due to protecting individual patient privacy but are available from the corresponding author on reasonable request.

\section{Competing Interest}

The manuscript has not been a podium or poster meeting. We declare that we have no financial and personal relationships with other people or organizations that can inappropriately influence our work, there is no professional or other personal interest of any nature or kind in any product, service and/or company that could be construed.

\section{Funding}

This study was supported by grants (No. 81874143, No. 31971192) from the National Nature Science Foundation of China, and Beijing Hospital Authority (No. QMS20201105). The funding body financed the costs of the study and contributed to the design of the study, interpretation of data, and revising the manuscript.

\section{Authors' contributions}

BCX contributed to the conception and design. KW and HWW are responsible for the provision of the study materials and data collection. WL and JML contributed to the data analysis and interpretation and draft writing equally. All authors read and approved the final manuscript.

\section{Acknowledgement}


No preregistration exists for the reported studies reported in this article. We acknowledge QB who contributed towards the study by making substantial contributions to the acquisition of the data and KMJ who made substantial contributions to the analysis and interpretation of the data. They are involved in drafting the manuscript but do not meet the criteria for authorship.

\section{References}

1. Leung U, Gonen M, Allen PJ, Kingham TP, DeMatteo RP, Jarnagin WR, D'Angelica MI: Colorectal Cancer Liver Metastases and Concurrent Extrahepatic Disease Treated With Resection. Ann Surg 2017, 265(1):158-165.

2. Kopetz S, Chang GJ, Overman MJ, Eng C, Sargent DJ, Larson DW, Grothey A, Vauthey JN, Nagorney DM, McWilliams RR: Improved survival in metastatic colorectal cancer is associated with adoption of hepatic resection and improved chemotherapy. J Clin Oncol 2009, 27(22):3677-3683.

3. Imai K, Allard MA, Benitez CC, Vibert E, Sa Cunha A, Cherqui D, Castaing D, Bismuth H, Baba H, Adam R: Early Recurrence After Hepatectomy for Colorectal Liver Metastases: What Optimal Definition and What Predictive Factors? Oncologist 2016, 21(7):887-894.

4. Wicherts DA, de Haas RJ, Salloum C, Andreani P, Pascal G, Sotirov D, Adam R, Castaing D, Azoulay D: Repeat hepatectomy for recurrent colorectal metastases. Br J Surg 2013, 100(6):808-818.

5. Butte JM, Gonen M, Allen PJ, Peter Kingham T, Sofocleous CT, DeMatteo RP, Fong Y, Kemeny NE, Jarnagin WR, D'Angelica MI: Recurrence After Partial Hepatectomy for Metastatic Colorectal Cancer: Potentially Curative Role of Salvage Repeat Resection. Ann Surg Oncol 2015, 22(8):2761-2771.

6. Adams RB, Aloia TA, Loyer E, Pawlik TM, Taouli B, Vauthey JN, Americas Hepato-Pancreato-Biliary A, Society of Surgical O, Society for Surgery of the Alimentary T: Selection for hepatic resection of colorectal liver metastases: expert consensus statement. HPB (Oxford) 2013, 15(2):91-103.

7. Therasse P, Arbuck SG, Eisenhauer EA, Wanders J, Kaplan RS, Rubinstein L, Verweij J, Van Glabbeke $\mathrm{M}$, van Oosterom AT, Christian MC et al: New guidelines to evaluate the response to treatment in solid tumors. European Organization for Research and Treatment of Cancer, National Cancer Institute of the United States, National Cancer Institute of Canada. J Natl Cancer Inst 2000, 92(3):205-216.

8. Nordlinger B, Sorbye H, Glimelius B, Poston GJ, Schlag PM, Rougier P, Bechstein WO, Primrose JN, Walpole ET, Finch-Jones $\mathrm{M}$ et al: Perioperative FOLFOX4 chemotherapy and surgery versus surgery alone for resectable liver metastases from colorectal cancer (EORTC 40983): long-term results of a randomised, controlled, phase 3 trial. Lancet Oncol 2013, 14(12):1208-1215.

9. Yan TD, Sim J, Black D, Niu R, Morris DL: Systematic review on safety and efficacy of repeat hepatectomy for recurrent liver metastases from colorectal carcinoma. Ann Surg Oncol 2007, 14(7):2069-2077.

10. Hof J, Wertenbroek MW, Peeters PM, Widder J, Sieders E, de Jong KP: Outcomes after resection and/or radiofrequency ablation for recurrence after treatment of colorectal liver metastases. $\mathrm{Br} \mathrm{J}$ Surg 2016, 103(8):1055-1062. 
11. Neal CP, Nana GR, Jones M, Cairns V, Ngu W, Isherwood J, Dennison AR, Garcea G: Repeat hepatectomy is independently associated with favorable long-term outcome in patients with colorectal liver metastases. Cancer Med 2017, 6(2):331-338.

12. Serrano PE, Gu CS, Husien M, Jalink D, Ritter A, Martel G, Tsang ME, Law CH, Hallet J, McAlister V et al: Risk factors for survival following recurrence after first liver resection for colorectal cancer liver metastases. J Surg Oncol 2019, 120(8):1420-1426.

13. Imai K, Allard MA, Castro Benitez C, Vibert E, Sa Cunha A, Cherqui D, Castaing D, Bismuth H, Baba H, Adam R: Nomogram for prediction of prognosis in patients with initially unresectable colorectal liver metastases. Br J Surg 2016, 103(5):590-599.

14. Luo LX, Yu ZY, Huang JW, Wu H: Selecting patients for a second hepatectomy for colorectal metastases: an systemic review and meta-analysis. Eur J Surg Oncol 2014, 40(9):1036-1048.

15. de Jong MC, Pulitano C, Ribero D, Strub J, Mentha G, Schulick RD, Choti MA, Aldrighetti L, Capussotti L, Pawlik TM: Rates and patterns of recurrence following curative intent surgery for colorectal liver metastasis: an international multi-institutional analysis of 1669 patients. Ann Surg 2009, 250(3):440448.

16. Vigano L, Capussotti L, Lapointe R, Barroso E, Hubert C, Giuliante F, ljzermans JN, Mirza DF, Elias D, Adam R: Early recurrence after liver resection for colorectal metastases: risk factors, prognosis, and treatment. A LiverMetSurvey-based study of 6,025 patients. Ann Surg Oncol 2014, 21(4):1276-1286.

17. Takahashi S, Konishi M, Kinoshita T, Gotohda N, Kato Y, Saito N, Sugito M, Yoshino T: Predictors for early recurrence after hepatectomy for initially unresectable colorectal liver metastasis. $J$ Gastrointest Surg 2013, 17(5):939-948.

18. Tan MC, Butte JM, Gonen M, Kemeny N, Fong Y, Allen PJ, Kingham TP, Dematteo RP, Jarnagin WR, D'Angelica Ml: Prognostic significance of early recurrence: a conditional survival analysis in patients with resected colorectal liver metastasis. HPB (Oxford) 2013, 15(10):803-813.

19. Imai K, Yamashita YI, Miyamoto Y, Nakagawa S, Okabe H, Hashimoto D, Chikamoto A, Baba H: The predictors and oncological outcomes of repeat surgery for recurrence after hepatectomy for colorectal liver metastases. Int J Clin Oncol 2018, 23(5):908-916.

20. Kulik U, Bektas H, Klempnauer J, Lehner F: Repeat liver resection for colorectal metastases. Br J Surg 2013, 100(7):926-932.

21. Andreou A, Brouquet A, Abdalla EK, Aloia TA, Curley SA, Vauthey JN: Repeat hepatectomy for recurrent colorectal liver metastases is associated with a high survival rate. HPB (Oxford) 2011, 13(11):774-782.

22. Battula N, Tsapralis D, Mayer D, Isaac J, Muiesan P, Sutcliffe RP, Bramhall S, Mirza D, Marudanayagam R: Repeat liver resection for recurrent colorectal metastases: a single-centre, 13year experience. HPB (Oxford) 2014, 16(2):157-163.

23. Ali MA, Di Sandro S, Lauterio A, Concone G, Mangoni I, Ferla F, Rotiroti V, Cusumano C, Giacomoni A, De Carlis L: Repeat Hepatectomy for Recurrent Colorectal Liver Metastases: Is it Worth the Challenge? J Gastrointest Surg 2015, 19(12):2192-2198. 
24. Oshowo A, Gillams AR, Lees WR, Taylor I: Radiofrequency ablation extends the scope of surgery in colorectal liver metastases. Eur J Surg Onco/ 2003, 29(3):244-247.

25. Evrard S, Becouarn Y, Fonck M, Brunet R, Mathoulin-Pelissier S, Picot V: Surgical treatment of liver metastases by radiofrequency ablation, resection, or in combination. Eur J Surg Oncol 2004, 30(4):399-406.

26. Valls C, Ramos E, Leiva D, Ruiz S, Martinez L, Rafecas A: Safety and Efficacy of Ultrasound-Guided Radiofrequency Ablation of Recurrent Colorectal Cancer Liver Metastases after Hepatectomy. Scand J Surg 2015, 104(3):169-175.

27. Solbiati L, Ahmed M, Cova L, lerace T, Brioschi M, Goldberg SN: Small liver colorectal metastases treated with percutaneous radiofrequency ablation: local response rate and long-term survival with up to 10-year follow-up. Radiology 2012, 265(3):958-968.

28. Veltri A, Sacchetto P, Tosetti I, Pagano E, Fava C, Gandini G: Radiofrequency ablation of colorectal liver metastases: small size favorably predicts technique effectiveness and survival. Cardiovasc Intervent Radio/ 2008, 31(5):948-956.

29. Hamada A, Yamakado K, Nakatsuka A, Uraki J, Kashima M, Takaki H, Yamanaka T, Inoue Y, Kusunoki $\mathrm{M}$, Takeda K: Radiofrequency ablation for colorectal liver metastases: prognostic factors in nonsurgical candidates. Jpn J Radiol 2012, 30(7):567-574.

30. Chua TC, Liauw W, Chu F, Morris DL: Viewing metastatic colorectal cancer as a curable chronic disease. Am J Clin Oncol 2012, 35(1):77-80.

\section{Tables}

Table 1. Demographic and clinical characteristics of patients after first recurrence 


\begin{tabular}{|c|c|c|c|}
\hline \multirow[t]{2}{*}{ Variable } & \multicolumn{2}{|l|}{ Local treatment } & \multirow[t]{2}{*}{ Systemic chemotherapy } \\
\hline & Repeat hepatic resection & RFA & \\
\hline Patients demographics & $\mathrm{n}=88$ & $\mathrm{n}=85$ & $\mathrm{n}=127$ \\
\hline Age $\bigotimes$ years $\rrbracket$ & $55.6 \pm 10.3$ & $57.7 \pm 9.3$ & $56.1 \pm 9.8$ \\
\hline Sex ration(M:F) & $57: 31$ & $59: 26$ & $80: 47$ \\
\hline \multicolumn{4}{|l|}{ Primary $\mathrm{T}$} \\
\hline T1-2 & 7 & 7 & 18 \\
\hline T3-4 & 81 & 78 & 109 \\
\hline \multicolumn{4}{|l|}{ Primary N } \\
\hline NO & 54 & 66 & 94 \\
\hline N1-2 & 34 & 19 & 33 \\
\hline \multicolumn{4}{|l|}{ Primary tumor location } \\
\hline Colon & 55 & 52 & 78 \\
\hline Rectum & 33 & 33 & 49 \\
\hline Right side & 24 & 17 & 34 \\
\hline Left side & 64 & 68 & 93 \\
\hline \multicolumn{4}{|l|}{ Timing of liver metastasis } \\
\hline Synchronous & 72 & 78 & 110 \\
\hline Metachronous & 16 & 7 & 17 \\
\hline Metastasis no. & $1(1-7)$ & $1(1-3)$ & $2(1-5)$ \\
\hline Metastasis size(mm) & $23.1 \pm 15.8$ & $15.6 \pm 1.7$ & $19.6 \pm 10.2$ \\
\hline \multicolumn{4}{|c|}{ Localization of liver metastases } \\
\hline unilobar & 63 & 70 & 64 \\
\hline bilobar & 25 & 15 & 55 \\
\hline$C E A>50$ & 13 & 4 & 5 \\
\hline CA199>100 & 10 & 6 & 8 \\
\hline \multicolumn{4}{|l|}{ Ras status } \\
\hline Wild & 62 & 50 & 77 \\
\hline Mutation & 26 & 35 & 50 \\
\hline
\end{tabular}


Table 1. Demographic and clinical characteristics of patients after first recurrence 


\begin{tabular}{|c|c|c|c|}
\hline \multirow[t]{2}{*}{ Variable } & \multicolumn{2}{|l|}{ Local treatment } & \multirow[t]{2}{*}{ Systemic chemotherapy } \\
\hline & Repeat hepatic resection & RFA & \\
\hline Patients demographics & $\mathrm{n}=88$ & $\mathrm{n}=85$ & $n=127$ \\
\hline Preoperative chemotherapy & 49 & 25 & 127 \\
\hline Up-front local treatment & 39 & 60 & 0 \\
\hline \multicolumn{4}{|l|}{ No. of lines } \\
\hline First line & 25 & 12 & 70 \\
\hline Second line & 24 & 13 & 47 \\
\hline Others & 0 & 0 & 15 \\
\hline \multicolumn{4}{|l|}{ Regimen } \\
\hline Oxaliplatin & 18 & 9 & 49 \\
\hline Irinotecan & 31 & 16 & 70 \\
\hline Others & 0 & 0 & 8 \\
\hline Biological agents & 39 & 20 & 95 \\
\hline Bevacizumab & 29 & 18 & 70 \\
\hline Cetuximab & 10 & 2 & 25 \\
\hline \multicolumn{4}{|l|}{ Response to chemotherapy } \\
\hline Complete & 0 & 0 & 0 \\
\hline Partial & 4 & 2 & 21 \\
\hline Stable disease & 41 & 23 & 89 \\
\hline Progressive disease & 0 & 0 & 17 \\
\hline \multicolumn{4}{|l|}{ Surgery details } \\
\hline Operation time & $204.4 \pm 89.0$ & NA & NA \\
\hline Blood lose & $274.1 \pm 77.1$ & NA & NA \\
\hline RBC transfusion & 2 & NA & NA \\
\hline $\mathrm{R} 1$ resection & 6 & NA & NA \\
\hline Complication & 4 & NA & NA \\
\hline Major & 1 & 0 & NA \\
\hline
\end{tabular}


Table 2. Univariable and multivariable analysis of factors associated with OS of CRLM after first recurrence 


\begin{tabular}{|c|c|c|c|c|c|c|}
\hline & \multicolumn{3}{|c|}{ Univariable analysis } & \multicolumn{3}{|c|}{ Multivariable analysis } \\
\hline & HR & $95 \%$ & $P$ value & HR & $95 \%$ & $P$ value \\
\hline \multicolumn{7}{|l|}{ Age } \\
\hline$\otimes 70$ & Ref & & & Ref & & \\
\hline$\leq 70$ & 1.462 & $0.869-2.461$ & 0.153 & 1.356 & $0.777-2.366$ & 0.284 \\
\hline \multicolumn{7}{|l|}{ Sex } \\
\hline Male & Ref & & & Ref & & \\
\hline Female & 0.941 & $0.670-1.322$ & 0.726 & 0.838 & $0.586-1.201$ & 0.336 \\
\hline \multicolumn{7}{|c|}{ Primary $\mathrm{T}$ stage } \\
\hline $1-2$ & Ref & & & Ref & & \\
\hline $3-4$ & 0.835 & $0.515-1.355$ & 0.465 & 0.846 & $0.502-1.424$ & 0.529 \\
\hline \multicolumn{7}{|c|}{ Primary N stage } \\
\hline No & Ref & & & Ref & & \\
\hline N1-2 & 1.860 & $1.265-2.734$ & 0.002 & 1.857 & $1.227-2.809$ & 0.003 \\
\hline \multicolumn{7}{|c|}{ Location tumor } \\
\hline Colon & Ref & & & Ref & & \\
\hline Rectum & 0.834 & $0.600-1.159$ & 0.279 & 0.783 & $0.517-1.187$ & 0.249 \\
\hline \multicolumn{7}{|c|}{ Primary tumor location } \\
\hline Left & Ref & & & Ref & & \\
\hline Right & 1.203 & $0.834-1.734$ & 0.322 & 1.233 & $0.770-1.973$ & 0.383 \\
\hline \multicolumn{7}{|c|}{ Timing of liver metastasis } \\
\hline ه12 month & Ref & & & Ref & & \\
\hline$\leq 12$ month & 0.981 & $0.588-1.435$ & 0.708 & 1.010 & $0.613-1.644$ & 0.970 \\
\hline \multicolumn{7}{|l|}{ CEA } \\
\hline$\$ 50$ & Ref & & & Ref & & \\
\hline$\leq 50$ & 0.798 & $0.451-1.443$ & 0.455 & 0.786 & $0.408-1.515$ & 0.472 \\
\hline \multicolumn{7}{|l|}{ CA199 } \\
\hline$\otimes 100$ & Ref & & & Ref & & \\
\hline$\leq 100$ & 1.154 & $0.675-1.974$ & 0.600 & 1.269 & $0.690-2.333$ & 0.444 \\
\hline
\end{tabular}


Table 2. Univariable and multivariable analysis of factors associated with OS of CRLM after first recurrence

\begin{tabular}{|c|c|c|c|c|c|c|}
\hline & \multicolumn{3}{|c|}{ Univariable analysis } & \multicolumn{3}{|c|}{ Multivariable analysis } \\
\hline & HR & $95 \%$ & $P$ value & HR & $95 \%$ & $P$ value \\
\hline \multicolumn{7}{|c|}{ Tumor size } \\
\hline$\leq 3 \mathrm{~cm}$ & Ref & & & Ref & & \\
\hline$\nabla 3 \mathrm{~cm}$ & 1.441 & $1.074-2.222$ & 0.035 & 1.707 & $1.037-2.810$ & 0.036 \\
\hline \multicolumn{7}{|c|}{ Tumor no. } \\
\hline$\leq 1$ & Ref & & & Ref & & \\
\hline$\nabla 1$ & 1.398 & $1.006-1.942$ & 0.046 & 0.733 & $0.424-1.268$ & 0.733 \\
\hline \multicolumn{7}{|c|}{ RAS status } \\
\hline Wild & Ref & & & Ref & & \\
\hline Mutation & 1.634 & $1.183-2.281$ & 0.003 & 1.553 & $1.080-2.234$ & 0.017 \\
\hline \multicolumn{7}{|c|}{ Distribution } \\
\hline Unilobar & Ref & & & Ref & & \\
\hline Bilobar & 1.553 & $1.094-2.205$ & 0.014 & 1.385 & $0.806-2.380$ & 0.238 \\
\hline \multicolumn{7}{|c|}{ Early recurrence } \\
\hline No & Ref & & & Ref & & \\
\hline Yes & 1.944 & $1.387-2.725$ & 0.000 & 1.702 & $1.148-2.523$ & 0.008 \\
\hline \multicolumn{7}{|c|}{ Local treatment } \\
\hline No & Ref & & & Ref & & \\
\hline Yes & 0.313 & $0.222-0.443$ & 0.000 & 0.322 & $0.218-0.467$ & 0.000 \\
\hline
\end{tabular}

\section{Figures}




\section{Kaplan-Meier Curve of OS}

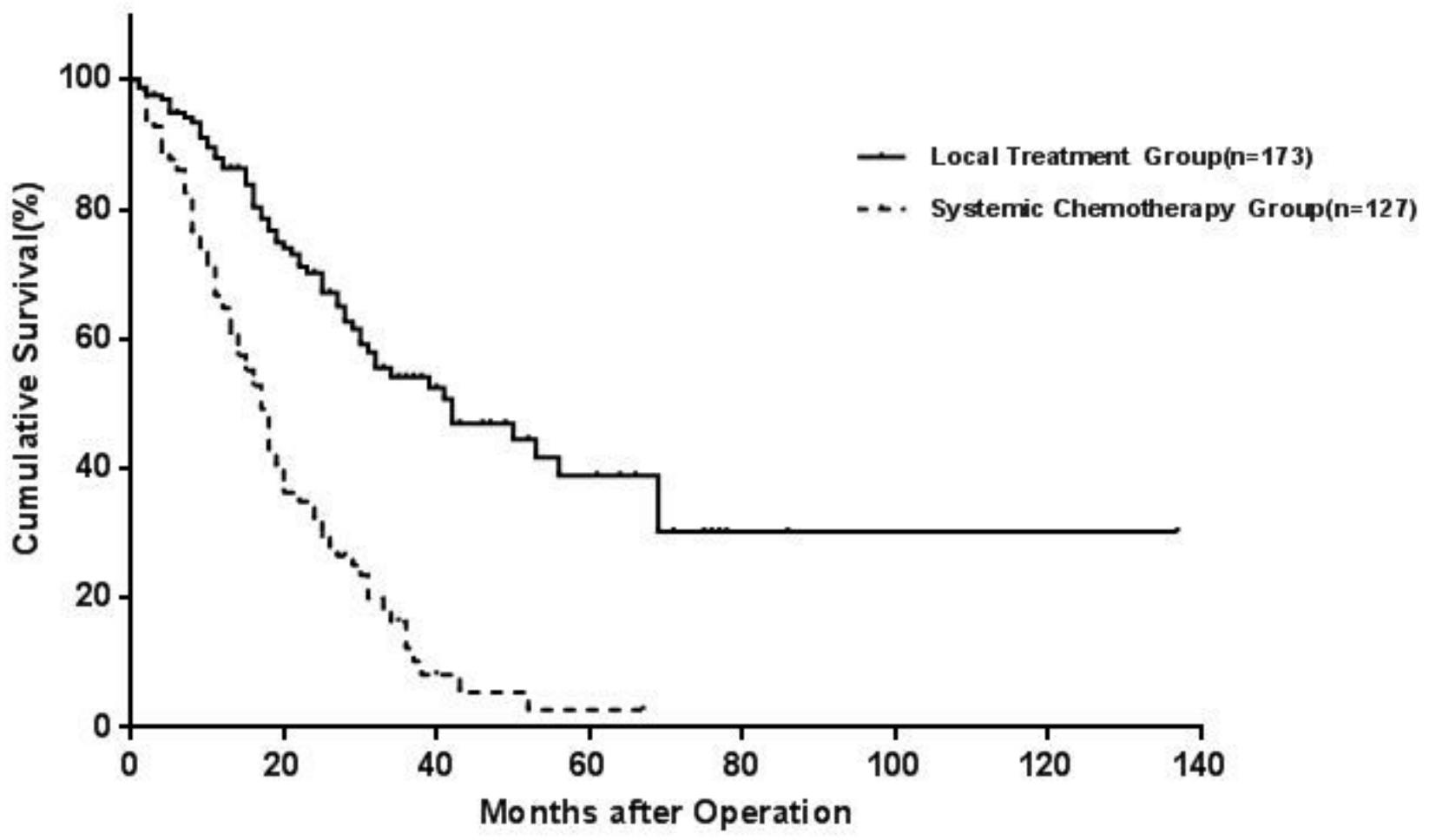

Figure 1

The OS of local treatment and chemotherapy was showed by Kaplan-Meier Curve. 
Points

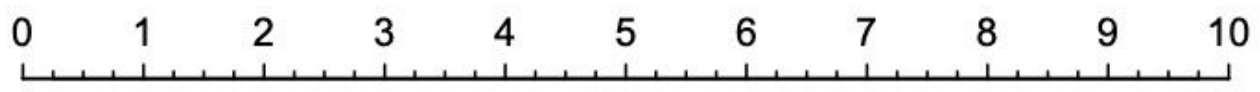

Early recurrrence

Node positive

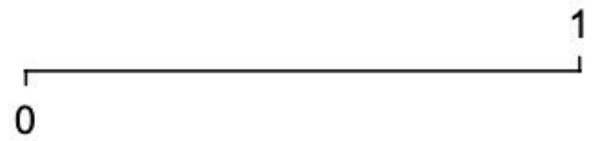

RAS mutation

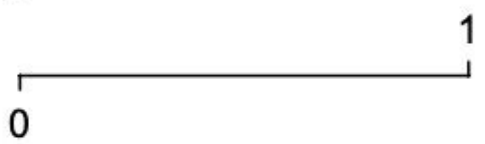

Local treatment

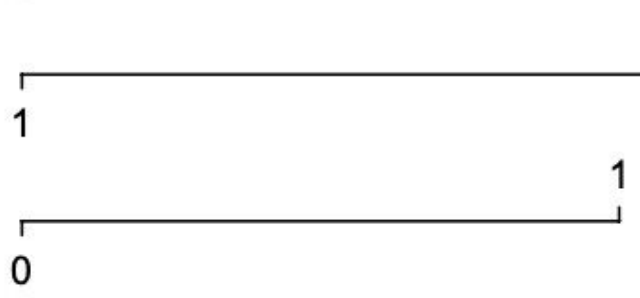

Total Points

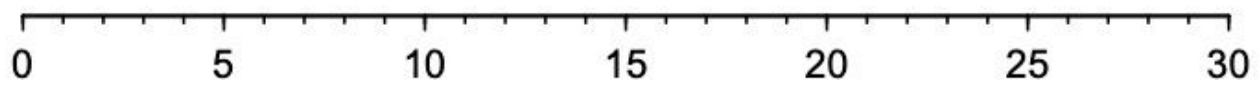

1-year Survival

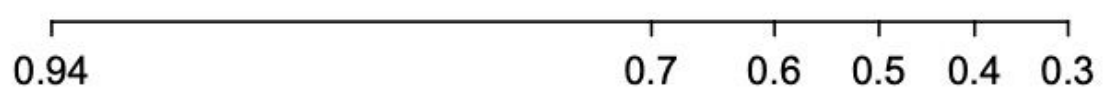

3-year Survival

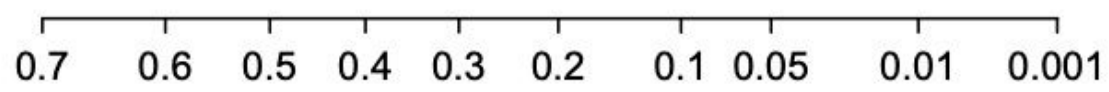

5-year Survival

\begin{tabular}{lllllllll}
\hline 0.6 & 0.5 & 0.4 & 0.3 & 0.2 & 0.1 & 0.05 & 0.01 & 0.001
\end{tabular}

Figure 2

Colorectal liver metastasis Nomogram for OS after First Recurrence. 

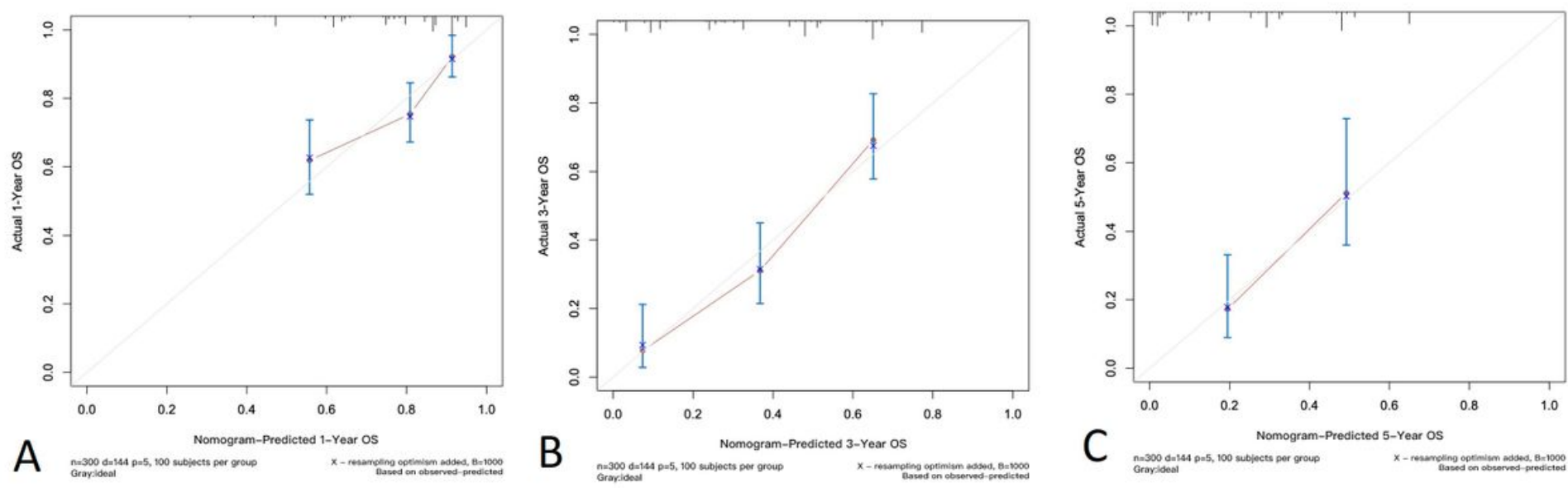

\section{Figure 3}

a. The predicting OS at 1-year by calibration curve. b. The predicting OS at 3-year by calibration curve. c. The predicting OS at 5-year by calibration curve.

\section{Supplementary Files}

This is a list of supplementary files associated with this preprint. Click to download.

- SupplementaryFigure1.pdf

- SupplementaryFigure2.jpg

- SupplementaryFigure3.jpeg

- SupplementaryFigure4.jpeg

- SupplementaryFigure5.jpg

- SupplementaryFigure6.jpeg

- SupplementaryFigure7.jpeg

- SupplementaryTable1.docx

- SupplementaryTable2.docx 